\title{
Analysis of Exotic Parasitic Infection in a Large Group of Imported Dogs Following an Animal Welfare Investigation
}

lan Wright ( $\sim$ hammondia@hotmail.com )

Mount Veterinary Practice

Vanessa Whitfield

RSPCA: Royal Society for the Prevention of Cruelty to Animals

Runa Hanaghan

Dogs Trust

Melissa Upjohn

Dogs Trust

Paula Boyden

Dogs Trust

\section{Research Article}

Keywords: Dogs, relocation, parasites, vectors, UK, testing, welfare

Posted Date: January 11th, 2022

DOI: https://doi.org/10.21203/rs.3.rs-1143197/v1

License: (c) (i) This work is licensed under a Creative Commons Attribution 4.0 International License.

Read Full License 


\section{Abstract}

Background: Increased dog relocation can cause dissemination of parasite and vector populations and this is being recognised in countries across Northern Europe, including the UK. Data regarding the prevalence of exotic infections entering the UK would be beneficial to vets to help assess pets entering the UK from abroad, and to help calculate risk of establishment of novel pathogens. One such group of dogs were seized as part of an RSPCA-led animal welfare investigation and blood tested for exotic pathogens.

Methods: As part of the RSPCA investigation, 151 dogs were removed from the site. Blood tests were performed for Babesia. canis, Ehrlichia canis, Hepatozoon canis and Leishmania infantum by PCR, Br.canis by antibody serology and D.immitis by blood antigen. In addition to pathogen screening, a serology titre for Rabies was measured for each dog. A clinical examination was performed by a veterinary surgeon and clinical signs recorded. Clinical signs data were analysed by the Fisher-FreemanHalton Exact Test

Results: Overall, $24 \%$ of the dogs tested positive for an infection. Two dogs were positive for Br.canis antibodies and had no clinical signs indicative of infection. Leishmania infantum was identified in $10.5 \%$ of dogs with all but two cases being diagnosed in dogs whose microchip originated in Romania. Hepatozoon canis was identified in $9.6 \%$ of dogs, all of which had a Romanian microchip. Dirofilaria immitis was identified in $4.1 \%$ of dogs, B.canis in $2.3 \%$ of dogs and E.canis was only present in $1.5 \%$ of dogs tested. Only four dogs were found to have co-infections. No significant association was found between the pathogens detected and presenting clinical signs.

Conclusions: This study demonstrates a range of exotic pathogens entering the UK including Br.canis and demonstrates the importance of screening imported dogs. The emphasis for early recognition of exotic pathogens in imported dogs has relied on screening based on relevant clinical signs and the country of origin. While these factors are useful, this study demonstrated no significant association between presenting clinical signs and the pathogens carried.

\section{Background}

The permanent relocation of dogs both within and between countries represents a global veterinary and public health concern. Many different factors affect canine welfare worldwide including natural disasters[1], persecution of street dogs[2], the canine meat trade[3], and puppy farming. The desire of the public to adopt dogs from abroad that have had their welfare compromised is increasing and as a result, dogs are often relocated over large geographical distances[2, 4, 5]. However, dog relocation can cause dissemination of parasite and vector populations and this is being recognised in countries across Northern Europe as dogs are relocated from Southern and Eastern Europe. In the UK, importation of dogs from continental Europe and Asia are increasing (Table 1.) and with them, novel parasites. Dogs infected with Dirofilaria repens[6, 7], Hepatazoon canis[8], Leishmania infantum[9], Linguatula serrata[10], Thelazia callipeada[11] and Mesocestoides spp [12] have all been recorded in dogs imported into the UK from 
abroad with cases of Dirofilaria immitis and Ehrlichia canis in imported dogs also being reported to the European Scientific Counsel for Companion Animal Parasites (ESCCAP) UK \& Ireland[13].

Table 1

Number of dogs imported to the UK annually on the Pet Travel Scheme and Balai Directive 2011-2018

\begin{tabular}{|llll|}
\hline Year & $\begin{array}{l}\text { Number of dogs imported via the Pet } \\
\text { Travel Scheme }\end{array}$ & $\begin{array}{l}\text { Number of dogs imported } \\
\text { via Balai }\end{array}$ & $\begin{array}{l}\text { Mixed } \\
\text { dog/cat }\end{array}$ \\
\hline 2011 & 85,299 & 4,625 & \\
\hline 2012 & 139,643 & 5,555 \\
\hline 2013 & 152,075 & 3,596 \\
\hline 2014 & 155,444 & 26,399 \\
\hline 2015 & 164,836 & 28,344 & 336 \\
\hline 2016 & 275,876 & 34,012 \\
\hline 2017 & 287,016 & 39,998 \\
\hline 2018 & 307,357 & 37,144 \\
\hline
\end{tabular}

The long incubation times associated with some infections and the wide range of possible clinical signs make recognition of infections and subsequent diagnosis difficult. This is especially true if multiple infections are present. Early recognition of clinical signs and diagnosis of exotic vector-borne infections is important however, to limit the risk of spread to local vectors or other animals. Cases of leishmaniosis have already been identified in untravelled UK dogs, possibly as a result of contact with dogs infected abroad[14, 15]. Babesia canis has also established in a focus of Dermacentor reticulatus ticks in Essex [16]. Early recognition and diagnosis are also important for long term management of chronic infections and early treatment intervention where this is appropriate to improve prognostic outcomes. Data regarding the prevalence of exotic infections entering the UK and how this differs depending on country of origin would be beneficial to vets to help assessment of pets entering the UK from abroad, as well as helping to calculate risk of establishment of pathogens that have UK vectors such as D.repens and B.canis. Currently these data do not exist beyond individual case reports and evaluation of the prevalence of vector-borne infections in a population of dogs that were imported from Southern or Eastern Europe would be of benefit in assessing these risks. One such group of dogs were seized as part of an RSPCA-led animal welfare investigation and blood tested for exotic pathogens. This investigation was referred to as Operation Cadmium.

4Paws Rescue and Transport was established in 2015 and was engaged in importing animals from eastern Europe into the UK for sale or adoption to members of the public or other rescue organisations. In 2017 over 4000 animals, the majority of which were dogs, were transported into the UK by 4Paws. In the period from 1.1.18 to 15.3 .18 , nearly 600 dogs were imported into the UK by 4Paws (see Figure 1). 
All dogs imported by 4Paws were imported under the Balai Directive as commercially imported dogs. The UK Government implements the Balai Directive under the Trade in Animals and Related Products Regulations 2011 which requires an importer to give notification to the Government regulating body (Animal Plant and Health Agency, APHA) on any commercially imported dog, ensure all dogs are identified with a microchip, and vaccinated against rabies, treated against the tapeworm Echinococcus multilocularis and issued with a Pet Passport certifying these (see Figure 2). Dogs imported by these methods must be kept at an import centre for at least 48 hours to allow them to be assessed. APHA runs a risk-based system on commercially imported dogs, setting a target to assess up to $5 \%$ of imported dogs against a trusted trader scheme. As dogs are checked at the point of destination, there are no checks at the ports i.e. at the point of entry into the UK.

Following the Operation Cadmium investigation several changes were made to the importation regulatory system including changing the risk basis for assessment of dogs and the risk basis under the trusted trader scheme. This investigation highlighted inadequacies in the underpinning European legislation which allows commercial importers the freedom to import an unlimited number of dogs as long as certain welfare and animal health rules are followed. The investigation asked questions about the appropriate level of risk assigned to organisations importing dogs regularly to the UK. It highlighted the risks for the UK and other countries on their ability to manage and control dog importation of this scale.

In Spring 2018 the RSPCA carried out an animal welfare investigation at 4Paws Rescue and Transport. Complaints had been received from former employees of 4 Paws and members of the public who had adopted animals from the establishment. There were reports of up to 200 dogs present at the site at any one time, that these dogs had been illegally imported and kept in filthy conditions with little disease control. Members of the public reported dogs were in ill health or even died post adoption. There were concerns about offences under multiple pieces of legislation including the Animal Welfare Act 2006, the Pet Animals Act 1951 and the Breeding and Sale of Dogs (Welfare) Act 1999. In partnership with the Police and supported by Dogs Trust, the RSPCA executed a warrant at the premises in March 2018. The RSPCA found animals' accommodation was soiled with urine and faeces, overcrowded and there was little water available. Some dogs were obviously unwell with coughing, plus nasal and ocular discharges seen. A dog was found dead in the veterinary clinic area and was subsequently found to have had distemper. Water had been purposely withheld from animals in the veterinary clinic to reduce urination in the cubicles. There were no biosecurity measures in place on the site (see Figure 3 ).

The veterinary surgeons who attended the site as part of Operation Cadmium concluded that there were multiple offences under the Animal Welfare Act 2006. At this point all of the animals resident on this site were certified to require removal to improve their welfare and meet their needs. This certification allowed the Police to seize (take possession of) all dogs and cats on the site. In total 151 dogs and puppies and 16 cats were removed. The attending veterinary surgeons deemed 11 dogs were in a suffering state. Causes of this suffering included skin and ear infections, infected wounds, respiratory infections, emaciation, a further case of distemper requiring euthanasia and severely restricted accommodation, lack of stimulation and companionship leading to mental oppression (see Figures 4). In addition, five offences 
of not providing adequately for the animals' needs were identified; provision of food and water, a suitable environment, protection from pain, injury and disease and an ability to express normal behaviours. All the animals received a full veterinary examination and any necessary investigations and treatment. Dogs were blood tested for imported (non-endemic) disease pathogen screening.

All dogs had observational behavioural assessment on site, with a follow-up by the same behaviourist approximately 6 weeks later. Approximately $70 \%$ of the dogs showed marked appeasement / displacement behaviours and a smaller proportion strong fearful / aggressive behaviour. Overcrowding, lack of choice, lack of isolation and competing for resources all contributed to welfare stress in these conditions and would have impacted the dogs' susceptibility to disease. Some dogs appeared to have come from a domestic background, whilst others were street dogs, the former being more resilient in the kennel environment.

Following this initial assessment there were a variety of outcomes for the animals removed from the 4Paws site. These included:

- The majority of the dogs were transferred to other imported dog rescues who had prior arrangements with 4Paws to take ownership of the animals

- A number of dogs were adopted by members of the public who had purchased dogs from 4Paws prior to the closure of the site.

- 25 dogs were transferred to and rehomed via Dogs Trust

- Two dogs which tested positive for Brucella canis were euthanased on the advice of APHA

- 12 dogs were retained in RSPCA care until the end of the case. Sadly, two of these dogs had to be euthanased on welfare grounds due to severe orthopaedic issues. The rest were rehomed at the conclusion of the case.

- All of the cats were retained in RSPCA care for a minimum of 6 months and had a full health assessment before being made available for adoption.

In September 2019 the owners of 4Paws were found guilty of causing unnecessary suffering to a number of animals and failing in their duty to provide adequately for the welfare needs of the animals in their care (see Figure 5).

\section{Methods}

Each animal removed during the investigation was scanned for a microchip at the time of the investigation. Signalment data including date of birth, sex, breed and microchip number were recorded, based on visual assessment at the time of the investigation, records held at the site of the operation and/or via microchip database. The source country for each dog was noted, based on the country of origin of the dog's microchip number. 
Blood was collected from each dog via jugular venepuncture and submitted to commercial laboratories (Animal and Plant Health Agency (APHA); IDEXX; Langford laboratories (Acarus)) to test for the following pathogens: B.canis, Br.canis, D.immitis, E.canis, H.canis, L.infantum. In addition to pathogen screening, a serology titre for Rabies was measured for each dog.

A clinical examination was performed by a veterinary surgeon and clinical signs recorded. Screening test results were recorded in a purpose-built Excel sheet as 'pass/fail', except for Rabies for which the numerical titre was recorded. Puppies under the age of eight weeks and accompanying their dam, were not tested.

\section{Results}

Signalment data for 147 dogs with at least partial records were summarised as follows:

\section{$\operatorname{Sex}(N=129)$}

$38 \%(49 / 129)$ of dogs were male.

\section{Age $(\mathrm{N}=94)$}

Median age was 1,088 days (Inter Quartile Range 428-1676 days).

\section{Breed $(\mathrm{N}=145)$}

23 different breeds/types were recorded, as well as 72 dogs recorded as 'cross': see Table 2 
Table 2

Breeds and types of dogs, listed in descending order of frequency.

\begin{tabular}{|ll|}
\hline Breed/type & Number of dogs \\
\hline Cross & 72 \\
\hline Terrier & 24 \\
\hline Bulldog & 9 \\
\hline Spaniel & 6 \\
\hline French Bulldog & 4 \\
\hline Labrador & 4 \\
\hline German Shepherd Dog & 3 \\
\hline Jack Russell Terrier & 3 \\
\hline Shi Tzu & 3 \\
\hline Bichon Frise & 2 \\
\hline Old English Sheepdog & 2 \\
\hline Bearded Collie & 1 \\
\hline Collie & 1 \\
\hline Dachshund & 1 \\
\hline Greyhound & 1 \\
\hline Poodle & 1 \\
\hline Pug & 1 \\
\hline Romanian Shepherd Dog & 1 \\
\hline Rottweiler & 1 \\
\hline St Bernard & 1 \\
\hline Schnauzer & 1 \\
\hline Spinone & 1 \\
\hline West Highland White Terrier & 1 \\
\hline Yorkshire Terrier & \\
\hline
\end{tabular}

\section{Countries Of Origin}


Four specific countries of origin, based on the source of the microchip, were identified as shown in Table 3:

Table 3

Country of origin of microchip, listed in descending order of frequency $(n=147)$

\begin{tabular}{|l|l|}
\hline Country of origin of microchip & Number of dogs \\
\hline Romania & 94 \\
\hline Unknown & 36 \\
\hline Hungary & 8 \\
\hline United Kingdom & 5 \\
\hline Republic of Ireland & 4 \\
\hline
\end{tabular}

Summary test results for each organism were as shown in Table 4:

Table 4

Summary results for each pathogen (n varies by individual pathogen)

\begin{tabular}{|llllll|}
\hline $\begin{array}{l}\text { Organism } \\
\text { species }\end{array}$ & Organism genus & Test & Number tested* & Positive tests & $\begin{array}{l}\text { Prevalence } \\
\%\end{array}$ \\
\hline Babesia & canis & PCR & 129 & 3 & 2.3 \\
\hline Brucella & canis & SAT & 113 & 2 & 1.7 \\
\hline Dirofilaria & immitis & Antigen & 121 & 5 & 4.1 \\
\hline Ehrlichia & canis & PCR & 131 & 2 & 1.5 \\
\hline Hepatozoon & canis & PCR & 104 & 10 & 9.6 \\
\hline $\begin{array}{l}\text { Leishmania } \\
\text { *NB Some missing data, complete test results were not recorded for all dogs. Prevalence estimate } \\
\text { reflects only those that were tested. }\end{array}$ & PCR & 133 & 10.5 \\
\hline
\end{tabular}

The two dogs which recorded positive Br.canis results had SAT measures:

$\operatorname{Dog} 12+/ 100$

Dog $22+/ 25$ A total of 32 dogs tested positive with an infection, with 36 positive tests recorded, see Table 4. Of these 28 dogs tested positive for one infection, and 4 dogs tested positive for co-infection of 2 diseases. One dog recorded positive for Br.canis and E.canis, one for Babesia canis and Leishmania canis, two dogs recorded positive for both H.canis and L.canis. All dogs that had co-infections had a Romanian microchip. 
One positive test result for L.canis was recorded in a dog from the UK (registered on Petlog through UK Kennel Club in 2016) and one for a dog of unknown origin. All other positive tests were recorded in imported dogs with a Romanian chip. For the 32 dogs recording at least one positive test, 12 were male (41\%), 17 were female, for 3 sex was not recorded. Median age for dogs with at least one positive test was 744 days ( $n=28$, for 4 positive dogs age was not recorded). Age ranges for dogs with positive results by pathogen are shown in Table 5:

Table 5

Age ranges for dogs with positive tests by pathogen:

\begin{tabular}{|lll|}
\hline Pathogen & $\begin{array}{l}\text { Minimum age for positive test } \\
\text { (days) }\end{array}$ & $\begin{array}{l}\text { Maximum age for positive test } \\
\text { (days) }\end{array}$ \\
\hline Babesia canis $(\mathrm{n}=3)$ & 343 & 1169 \\
\hline Brucella canis $(\mathrm{n}=2)$ & 435 & 744 \\
\hline Dirofilaria immitis $(\mathrm{n}=5)$ & 717 & 3132 \\
\hline Ehrlichia canis $(\mathrm{n}=2)$ & 435 & 5908 \\
$\begin{array}{l}\text { Hepatozoon canis } \\
(\mathrm{n}=10)\end{array}$ & 82 & 1453 \\
$\begin{array}{l}\text { Leishmania canis } \\
(\mathrm{n}=14)\end{array}$ & 385 & 6170 \\
\hline
\end{tabular}

Summary results for rabies serology by country of origin of microchip are shown in Table 6.

Table 6

Summary rabies serology results by country of origin of microchip $(n=129)$

\begin{tabular}{|llll|}
\hline $\begin{array}{l}\text { Country of Origin } \\
\text { of microchip }\end{array}$ & $\begin{array}{l}\text { Number } \\
\text { tested }\end{array}$ & $\begin{array}{l}\text { Number of Rabies AB } \\
\text { fail (<0.5) (\%) }\end{array}$ & $\begin{array}{l}\text { Of these fails, Number of Rabies AB } \\
<0.1 \text { (\% of all fails) }\end{array}$ \\
\hline UK & 5 & $4(80 \%)$ & $3(75 \%)$ \\
\hline Hungary & 7 & $4(57 \%)$ & $2(50 \%)$ \\
$\begin{array}{l}\text { Republic of } \\
\text { Ireland }\end{array}$ & 4 & $4(100 \%)$ & $0(0 \%)$ \\
\hline Romania & 79 & $50(70 \%)$ & $9(18 \%)$ \\
\hline $\begin{array}{l}\text { Unknown/missing } \\
\text { *NB Some missing data, test results were not recorded for all dogs. Prevalence estimate reflects only } \\
\text { those that were tested. }\end{array}$ & 34 & $32(94 \%)$ & $10(31 \%)$ \\
\hline
\end{tabular}

Note that the UK origin dog which did not fail Rabies AB test had a UK issued passport, so may have been vaccinated as part of international travel arrangements. 
Summary results for presenting clinical signs are shown in Table 7

Table 7

Most common presenting clinical signs recorded overall and for dogs with positive infectious disease test results

\begin{tabular}{|c|c|c|c|c|c|c|c|}
\hline $\begin{array}{l}\text { Clinical } \\
\text { sign }\end{array}$ & $\begin{array}{l}\text { Number } \\
\text { of dogs } \\
\text { affected } \\
(n=132)\end{array}$ & $\begin{array}{l}\text { Babesia } \\
\text { canis } \\
(\mathrm{n}=3)\end{array}$ & $\begin{array}{l}\text { Brucella } \\
\text { canis } \\
(\mathrm{n}=2)\end{array}$ & $\begin{array}{l}\text { Dirofilaria } \\
\text { immitis } \\
(\mathrm{n}=5)\end{array}$ & $\begin{array}{l}\text { Ehrlichia } \\
\text { canis } \\
(\mathrm{n}=2)\end{array}$ & $\begin{array}{l}\text { Hepatazoon } \\
\text { canis } \\
(\mathrm{n}=10)\end{array}$ & $\begin{array}{l}\text { Leishmania } \\
\text { infantum } \\
(\mathrm{n}=14)\end{array}$ \\
\hline $\begin{array}{l}\text { Poor body } \\
\text { condition }\end{array}$ & $\begin{array}{l}11 \\
(8.3 \%)\end{array}$ & 0 & 0 & 0 & 0 & $\begin{array}{l}1 \\
(10 \%)\end{array}$ & $\begin{array}{l}2 \\
(14.3 \%)\end{array}$ \\
\hline Pyrexia & $\begin{array}{l}9 \\
(6.8 \%)\end{array}$ & 0 & 0 & 0 & 0 & $\begin{array}{l}1 \\
(10 \%)\end{array}$ & $\begin{array}{l}1 \\
(7.1 \%)\end{array}$ \\
\hline $\begin{array}{l}\text { Skin } \\
\text { disease }\end{array}$ & $\begin{array}{l}26 \\
(19.7 \%)\end{array}$ & $\begin{array}{l}1 \\
(33.3 \%)\end{array}$ & $\begin{array}{l}1 \\
(50 \%)\end{array}$ & 0 & 0 & 0 & $\begin{array}{l}5 \\
(35.7 \%)\end{array}$ \\
\hline $\begin{array}{l}\text { Ocular } \\
\text { signs }\end{array}$ & $\begin{array}{l}30 \\
(22.7 \%)\end{array}$ & 0 & 0 & $\begin{array}{l}2 \\
(40 \%)\end{array}$ & $\begin{array}{l}1 \\
(50 \%)\end{array}$ & $\begin{array}{l}1 \\
(10 \%)\end{array}$ & $\begin{array}{l}4 \\
(28.6 \%)\end{array}$ \\
\hline $\begin{array}{l}\text { Otitis } \\
\text { externa }\end{array}$ & $\begin{array}{l}7 \\
(5.4 \%)\end{array}$ & 0 & 0 & 0 & 0 & 0 & 0 \\
\hline Respiratory & $\begin{array}{l}9 \\
(6.8 \%)\end{array}$ & 0 & $\begin{array}{l}1 \\
(50 \%)\end{array}$ & $\begin{array}{l}1 \\
(20 \%)\end{array}$ & 0 & $\begin{array}{l}1 \\
(10 \%)\end{array}$ & $\begin{array}{l}2 \\
(14.3 \%)\end{array}$ \\
\hline Gingivitis & $\begin{array}{l}3 \\
(2.3 \%)\end{array}$ & 0 & 0 & 0 & 0 & 0 & 0 \\
\hline $\begin{array}{l}\text { Enlarged } \\
\text { lymph } \\
\text { nodes }\end{array}$ & $\begin{array}{l}3 \\
(2.3 \%)\end{array}$ & 0 & 0 & 0 & 0 & 0 & 0 \\
\hline
\end{tabular}

Poor body condition - Classified as dogs with a body condition score of $2 / 9$ or less or with a body condition score of $1 / 5$ or less.

Pyrexia - Classified as a body temperature of 39.7 degrees Celsius or above

Skin disease - Pyoderma, erythema, alopecia, scurf, skin nodules or any combination of these signs.

Ocular - Keratitis, conjunctivitis, lens opacities, corneal opacities, chemosis or any combination of these signs. 
Respiratory - coughing, nasal discharge or wheezing.

There was no apparent relationship in this group of dogs between the pathogens detected and presenting clinical signs. A selected number of dogs were tested for canine distemper virus based on their clinical signs. Two dogs tested positive.

\section{Discussion}

This study represents the first reported dataset of exotic parasites in a group of dogs imported into the UK rather than individual or small groups of case reports. Such datasets are vital in establishing the prevalence of exotic parasites entering the UK in imported dogs, their geographic origin distribution and to facilitate investigation of risk factors for their presence.

Overall, $24 \%$ of the dogs tested positive for an infection listed in Table 4. Five of the six infections detected are currently not thought to be endemic in the UK and all of the detected infections are potentially pathogenic in dogs.

Importation of Br.canis is of particular concern, given its zoonotic potential, economic impact and risk of establishment in the UK. As a result, the RSPCA sought guidance from APHA on Brucella screening. $B R$.canis (canine brucellosis) is an important cause of abortions and infertility in dogs and has been recognised as the cause of significant economic loss in infected kennels. Canine brucellosis is mainly caused by Br.canis, and sporadically by Brucella melitensis, Brucella suis, and Brucella abortus. Brucella canis infected dogs can transmit the disease even after the bacteremia has ceased and without presenting clinical symptoms of the disease and it is also considered to be a zoonosis. The UK is currently considered to be free of Br.canis though two clinical cases were reported in 2017 [17].

APHA advised that Br.canis screening would be highly prudent before considering rehoming imported dogs to members of the public. An alert was issued to the veterinary profession by the UK Chief Veterinary Officer following the APHA's involvement in an investigation of cases in 2020[18]. The risk of infection with other Brucella species was also discussed. Concerns were raised over the possibility that Brucella canis could become endemic in the UK.

It was felt that dogs may be at high risk of acquiring infection with $B$. abortus, B. melitensis or $B$. suis if they live on farms where these pathogens are present, particularly if they come in to contact with abortion material or if they are used for hunting feral pigs and wild boar. In the vast majority of cases, antibodies to B. abortus, B. melitensis or B. suis will not be detected by the Br.canis serological assay (and vice versa). In the absence of history of this nature, it was felt that screening for species of Brucella, other than Br.canis, was not necessary in imported dogs. Therefore, dogs in this cohort were screened for Br.canis only.

Any dogs that had a positive antibody tire on initial screening had a repeat sample sent to the APHA lab at Weybridge approximately 5 weeks after the first sample was analysed. From the 4 samples submitted, 
two of these dogs tested negative while two tested positive on APHA's SAT for Br.canis antibody.APHA informed the RSPCA that these dogs should be euthanased on infection control grounds. The RSPCA had been unable to identify an owner of one of the dogs while informed consent for euthanasia was gained for the other. If there had been issues with gaining consent for euthanasia, APHA would have issued a destruction order. Both dogs were sedated and examined prior to euthanasia and were found to be clinically normal other than minor dental trauma in one, one with a mild cough and one mildly underweight with a puncture wound on the pinna (registered as skin disease in the table). Hence it is important to note that clinical signs attributable to Brucella canis infection may not be apparent on physical examination of imported dogs.

Leishmania infantum was identified in 14 positive dogs (10.5\%), the most diagnosed parasite with all but two cases being diagnosed in dogs whose microchip originated in Romania. While this does not mean that these infections all originated in Romania, L.infantum is now considered to be at least seasonally endemic in the country [19]. It is important therefore that UK vets consider the possibility of L.infantum infection in imported dogs. Dogs on presentation may be subclinical as clinical signs take months and sometimes years after infection to manifest. Early recognition of infection by diagnostic screening of imported dogs would allow monitoring of kidney function and antibody titres so treatment can be initiated at an early clinical stage. This has been demonstrated to improve prognostic outcomes, particularly if significant proteinuria and renal failure can be avoided [20]. Identification of infected dogs is also important to prevent transmission to other UK dogs. Although the sand fly vector is currently not currently thought to be present in the UK, non-vectoral transmission via venereal and transplacental transmission, blood transfusion and possibly dog bites can also occur. Two cases of unexplained horizontal transmission have already occurred in untraveled UK dogs [14,15]. Early identification of positive dogs means that measures to limit spread can be implemented such as excluding infected dogs from breeding and from being blood donors.

Hepatazoon canis was identified in 10 dogs (9.6\%), all of which had a Romanian microchip. This parasite is not considered endemic in Romania, so this finding supports the suggestion that Romania may be acting as a hub for dogs being relocated from other countries. It is important that UK vets, however, are aware of its possible presence in dogs imported from Romania and consider it as a differential if these dogs present with fever or lymphadenopathy. Imported dogs can be screened for the parasite through blood smears with $0.5-5 \%$ of neutrophils commonly infected, although this figure can be as high as $100 \%$ [21].

Ehrlichia canis, which is endemic in Romania was only present in 2 (1.5\%) of dogs tested. Nonetheless this pathogen is highly pathogenic and often fatal if chronic ehrlichiosis develops. This can occur months or years after initial infection and can be avoided if acute infections are treated adequately. Screening of imported dogs is therefore important, both to treat dogs suffering from acute ehrlichiosis and to monitor chronically infected dogs so that chronic disease can be treated early to maximise positive outcomes. Both H.canis and E.canis have been recorded in imported dogs $[22,23]$ but are not thought to be currently endemic. The tick Rhipicephalus sanguineus which is required for transmission is not endemic in the UK

Page $12 / 22$ 
outside of individual household infestations. It is however, important that imported dogs are checked and treated for ticks as R.sanguineus can establish in UK homes and then go on to transmit these pathogens[24].

Dirofilaria immitis was identified in $5(4.1 \%)$ of dogs. Increasing numbers of imported dogs infected with D.immitis are being reported to the European Scientific Counsel for Companion Animal Parasites (ESCCAP) UK \& Ireland, with many of them coming from Eastern Europe[23]. Dirofilaria immitis has spread through Eastern Europe with Romania now having been confirmed as endemic for the parasite [25]. The mosquito vectors required for transmission are present throughout Europe but it is currently not warm enough for D.immitis to complete its life cycle in the UK [26]. It is vital to screen imported pets for the parasite however, as adult worms can cause heart and respiratory disease as well as sudden death through thromboembolism. Identification of the parasite allows effective treatment protocols to be put in place while minimising the risk of thromboembolism through strict rest of the patient. Dogs with undiagnosed heartworm infection can also suffer anaphylaxis as a result of routine use of macrocyclic lactones for other parasite prevention [27].

Three $(2.3 \%)$ of the dogs tested were positive for B.canis. Babesia.canis is transmitted by the tick Dermacentor reticulatus and is endemic throughout mainland Europe. Pockets of D.reticulatus have been long established in West Wales, Devon, and the South East of England and while B.canis had been absent from the UK, these ticks present an opportunity for it to become endemic if introduced through dogs entering the UK from abroad. An endemic focus of Babesia canis infection established in Harlow, Essex in 2015, with B.canis confirmed in local Dermacentorticks and in untravelled dogs [16]. Further untravelled cases were confirmed in Romford in 2016 and Ware in 2017 [28]. This demonstrates the importance of vigilance for B.canis in imported dogs to prevent exposure of local populations of D.reticulatus ticks, but also so infected dogs can be monitored for the development of immune mediated haemolytic anaemia and thrombocytopenia [29]. Treatment initiated early for clinical babesiosis improves prognostic outcomes [30].

Only four dogs were found to have co-infections. Other studies have found E.canis infection to be a risk factor for L.infantum infection[31]. This is not supported by this study. It is possible that those dogs infected with L.infantum and those infected with H.canis were exposed in different regions/countries and opportunity for exposure to both pathogens did not occur. This is not possible to confirm however, without an accurate travel history for the tested dogs.

There was no association found between the pathogens detected and presenting clinical signs in this group for dogs. This is concerning as veterinary professionals rely in part on recognition of relevant clinical signs to alert them to potential exotic infections in imported pets. The lack of a relationship in this study emphasises the importance of screening for exotic pathogens if these are to be detected. The exception was L.infantum where A high proportion of L.infantum positive dogs had ocular and dermatological signs. If dogs with dermatological and/or ocular signs had both been used collectively as 
criteria for testing alongside poor body condition score and pyrexia, then all but one of the Leishmania positive dogs would have been identified.

Large numbers of dogs in the group had ocular (22.8\%) and dermatological (19.7\%) signs. This is of concern as D.repens and T.callipaeda may have been responsible for some of these cases and gone undetected. Dogs having spent time in countries endemic for these parasites with ocular and/or dermatological signs should be thoroughly examined for these parasites and in the case of D.repens, a modified knotts test performed.

Of the 129 dogs tested for rabies serology $94(72.8 \%)$ had a titre less than $0.5 \mathrm{IU} / \mathrm{ml}$, with $24(18.6 \%)$ having a titre less than $0.1 \mathrm{lU} / \mathrm{ml}$. Whilst it cannot be assumed that a low titre equates to no protection against rabies, the proportion of dogs with low titres is of concern. Previous studies have shown that there are differences between vaccines [33] with an overall failure rate of $4.12 \%(14,035$ samples). With this sample showing that $72.8 \%$ of the imported dogs did not have a protective titre raised the question whether the dogs had been vaccinated at all. Titres less than $0.1 \mathrm{IU} / \mathrm{ml}$ are considered negative for the fluorescent antibody virus neutralisation assay. With the prevalence of disease identified it is also important to question whether the poor response could be associated with underlying disease.

Regarding the 2 dogs diagnosed with canine distemper virus (CDV) the most common route of transmission of CDV is direct contact via the oronasal secretions of infected animals [32]. Indirect transmission plays only a minor role as the virus is quickly inactivated. The concern with this is the similarity in some of the symptoms to those of other neurological conditions in imported dogs particularly rabies. Recent studies [34] emphasise the risk of introducing vector borne disease and diseases not considered endemic into naïve countries by non-vaccinated rescue dog importations.

The microchips of the majority of dogs (94 of 140) originated in Romania and these dogs accounted for all but two cases of infection recorded. Romania is recognised as a common source of imported rescue dogs, driven in part by the large number of street dogs present there and Government policy of euthanising street dogs that cannot be rapidly rehomed. The large numbers of rescued imported Romanian dogs entering the UK and being presented in veterinary practices means that UK veterinary professionals need to be aware of parasites likely to be present in these dogs, possible presenting clinical signs, the need for diagnostic tests and medical management where appropriate. Although microchips can be traced to an individual country, it does not guarantee the microchipped dogs originated there and may have been imported into a country prior to microchipping. This means pathogens not thought to be endemic in the country where the microchip originated may still be present.

\section{Conclusion}

This study demonstrated a range of parasites exotic to the UK in dogs rescued from abroad with L.infantum and H.canis having the greatest prevalence in the group. A high proportion of the dogs tested positive for one of more pathogens not confirmed to be currently endemic in the UK. The six exotic pathogens diagnosed carry health risks to the infected dogs, significant risk of establishment in the UK 
and in the case of B.canis, direct zoonotic risk. The group of dogs tested represent a very small proportion of the total number of dogs being rescued and imported into the UK each year with no mandatory testing for exotic parasites they may be carrying and no national reporting when these tests are performed.

Studies such as this one are therefore essential to establish which pathogens may be entering the UK and in what numbers. Increasing both veterinary and public awareness of the likelihood of exotic pathogens being present in imported dogs is also vital so they can be considered as differentials of disease and relevant screening tests can be performed. It would be useful to correlate clinical signs with specific infections. Although this was not possible in this study, patterns useful to practitioners may emerge in larger studies, making these of benefit in the future.

\section{Abbreviations}

CDV

Cannie distemper virus

ESCCAP

European scientific council for companion animal parasites

\section{Declarations}

\section{Ethics approval and consent to participate}

Not applicable.

\section{Consent for publication}

Not applicable.

\section{Availability of data and materials}

All data generated or analysed during this study are included in this published article [and its supplementary information files].

\section{Competing interests}

The authors declare that they have no competing interests.

\section{Authors' contributions}

IW was the primary contributor in writing the manuscript and contributed to data analysis.

VW contributed to gathering data, writing the operation cadmium section of them manuscript, and providing images.

$\mathrm{RH}$ contributed to data gathering, interpretation and analysis 
MU contributed to collating, interpreting, and analysing data and in collating references.

PB contributed to writing the manuscript.

All authors read and approved the final manuscript.

\section{Funding}

All sources of funding for the research reported should be declared. The role of the funding body in the design of the study and collection, analysis, and interpretation of data and in writing the manuscript should be declared.

\section{Acknowledgements}

Thank you to Katharine Anderson, Catherine Dobbie and Liz Taylor for their assistance with data management.

Thank you to the RSPCA Special Operations Unit for providing data used in this study

Thank you to Steve Goward for providing behavioural assessment advice

\section{References}

1. Heath SE, Linnabary RD. Challenges of Managing Animals in Disasters in the U.S. Animals (Basel). 2015;5:173-92.

2. Norman C, Stavisky J, Westgarth C. Importing rescue dogs in the UK: reasons, methods and welfare considerations. Vet Rec. 2020;186(8):248.

3. Dugnoille J. From plate to pet: Promotion of trans-species companionship by Korean animal activists. Anthropol Today. 2014;30:3-7.

4. Simmons KE, Hoffman CL. Dogs on the Move: Factors Impacting Animal Shelter and Rescue Organizations' Decisions to Accept Dogs from Distant Locations. Animals (Basel). 2016;6(2):11.

5. Drake J, Parrish RS. Dog importation and changes in heartworm prevalence in Colorado 2013-2017. Parasit Vectors. 2019;12:207.

6. Agapito D, Aziz N-AA, Wang T, Morgan ER. \& Wright I. Subconjunctival Dirofilaria repens infection in a dog resident in the UK. J Small Anim Pract. 2017;59:50-2.

7. Wright I. Case report: Dirofilaria repens in a canine castrate incision. Companion Anim. 2017;22:3168.

8. Attipa C, Maguire D, Solano-Gallego L, Szladovits B, Barker EN, Farr A, et al. Hepatozoon canis in three imported dogs: a new tickborne disease reaching the United Kingdom. Vet Rec. 2018;183:716.

9. Silvestrini P, Batchelor D, Allenspach K, Maunder C, Seth M, et al. Clinical leishmaniasis in dogs living in the UK. J Small Anim Pract. 2016;57:453-8. 
10. Mitchell S, Bell S, Wright I, Wall R, Jeckel S, et al. Tongue worm (Linguatula species) in stray dogs imported into the UK. Vet Rec. 2016;179:259-60.

11. Graham-Brown J, Gilmore P, Colella V, Moss L, Dixon C, et al. Three cases of imported eyeworm infection in dogs: a new threat for the United Kingdom. Vet Rec. 2017;181:346-50.

12. Wright I, Collins M, McGarry J, Teodoru S, Stoian C, et al. Threat of exotic worms in dogs imported from Romania. Vet Rec. 2020;187:348-9.

13. Wright I. Parasite prevention in the travelling pet. Companion Anim. 2019;24.4: 174.

14. McKenna M, Attipa C, Tasker S, Augusto M. Leishmaniosis in a dog with no travel history outside of the UK. Vet Rec. 2019;184:441.

15. Wright I, Baker S. Leishmaniosis in a dog with no history of travel outside the UK. Vet Rec. 2019;184:387-8.

16. Phipps L, Del MF De Marco, Hernández-Triana M, Johnson L, Swainsbury N. C et al. Babesia canis detected in dogs and associated ticks from Essex. Vet Rec. 2016;178:243-4.

17. Whatmore AM, Perrett L, Friggens M. Second UK isolation of Brucella canis. Vet Rec. 2017;180:617.

18. Middlemiss C. Brucella Canis in dogs in the UK. Vet Rec. 2021;188(4):155.

19. Dumitrache MO, Nachum-Biala, Gilad Y, Mircean V, Cazan CD, et al. The quest for canine leishmaniasis in Romania: the presence of an autochthonous focus with subclinical infections in an area where disease occurred. Parasit Vectors. 2016;9:297.

20. Solano-Gallego L, Koutinas A, Miró G, Cardoso L, Pennisi MG, Ferrer L, et al. Directions for the diagnosis, clinical staging, treatment and prevention of canine leishmaniosis. Vet Parasitol. 2009;165:1-18.

21. Baneth G, Shkap V, Presentey BZ, Pipano E. Hepatozoon canis: the prevalence of antibodies and gametocytes in dogs in Israel. Vet Res Commun. 1996;20:41-6.

22. Attipa C, Maguire D, Solano-Gallego L, Szladovits B, Barker EN, et al. Hepatozoon canis in three imported dogs: a new tick-borne disease reaching the United Kingdom. Vet Rec. 2018;183:716.

23. Stokes L. \& Wright I. Parasite roundup 2017. Companion Animal. 2018;23:33-40.

24. Hansford KM, Pietzsch M, Cull M, Medlock JM. Brown dog tick infestation of a home in England. Vet Rec. 2015;176:129-30.

25. Ciuca L, Musella V, Miron L, Maurelli MP, Cringoli G, et al. \& Bosco. Geographic distribution of canine heartworm (Dirofilaria immitis) infection in stray dogs of eastern Romania. Geospat Health. 2016;11:499.

26. Lloyd S. Fly-borne parasitic disease: risk for the travelling pet. The Veterinary Nurse. 2011;2:295-301.

27. Ames MK, Atkins CE. Treatment of dogs with severe heartworm disease. Vet Parasitol. 2020;283:109131.

28. Wright I. Babesiosis in Essex, UK: monitoring and learning lessons from a novel disease outbreak. Parasit Vectors. 2018;11:132. 
29. de Marco MdMF, Hernández-Triana LM, Phipps LP, et al. Emergence of Babesia canis in southern England. Parasit Vectors. 2017;10:241. https://doi.org/10.1186/s13071-017-2178-5.

30. Eichenberger RM, Riond B, Willi B, Hofmann-Lehmann R, Deplazes P. Prognostic markers in acute Babesia canis infections. J Vet Intern Med. 2016;230:174-82.

31. Attipa C, Solano-Gallego L, Papasouliotis K, et al. Association between canine leishmaniosis and Ehrlichia canis co-infection: a prospective case-control study. Parasit Vectors. 2018;11:184.

32. Appel MJ. Pathogenesis of canine distemper. Am J Vet Res. 1969;30(7):1167-82.

33. Mansfield, et al. Factors affecting the serological response of dogs and cats to rabies vaccination. Vet Rec. 2004;154:423-6.

34. Willi B, Spiri AM, Meli ML, et al. Clinical and molecular investigation of a canine distemper outbreak and vector-borne infections in a group of rescue dogs imported from Hungary to Switzerland. BMC Vet Res. 2015;11:154.

\section{Figures}

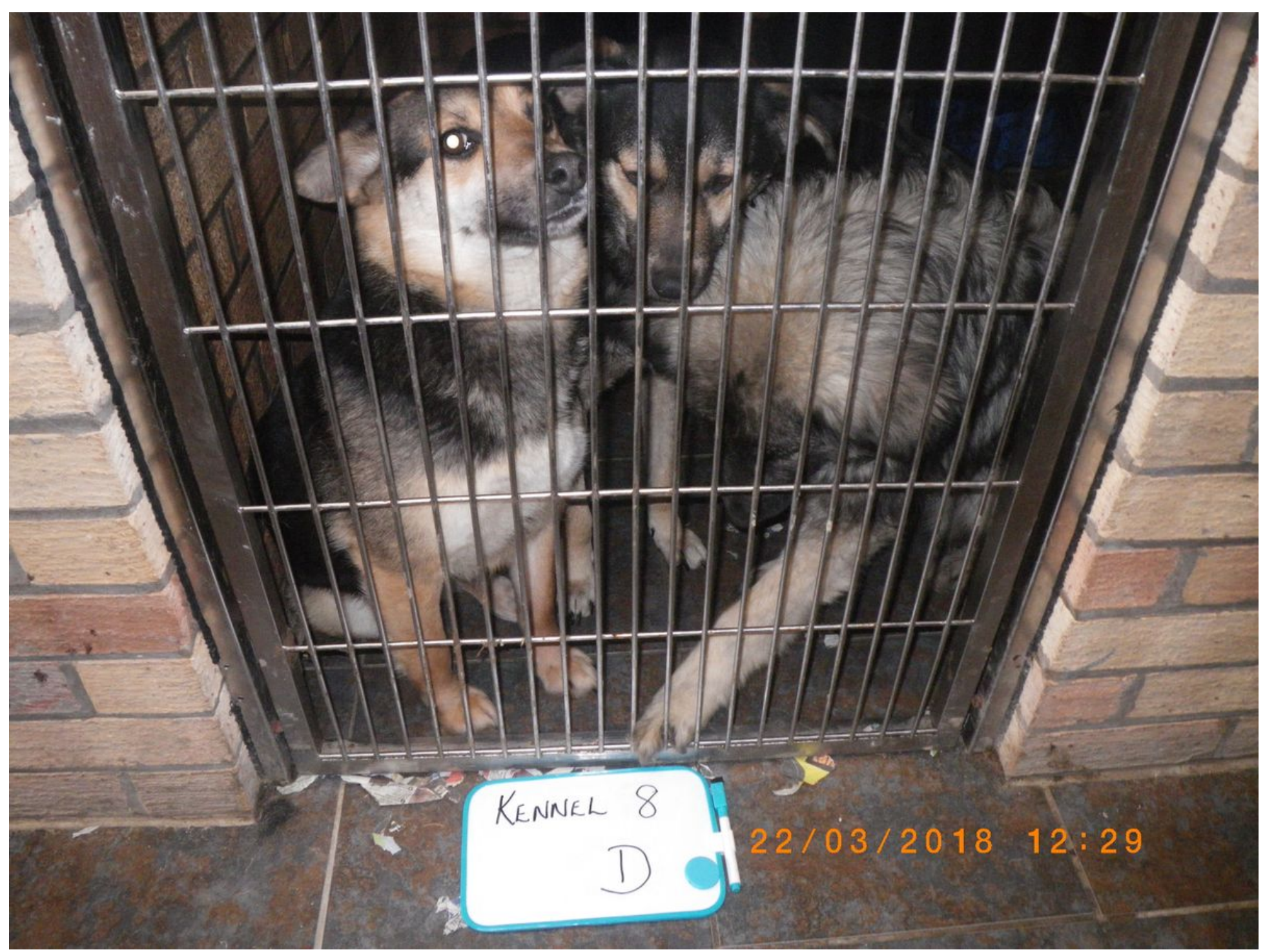




\section{Figure 1}

Dogs imported to the UK to be sold or rehomed to members of the public.

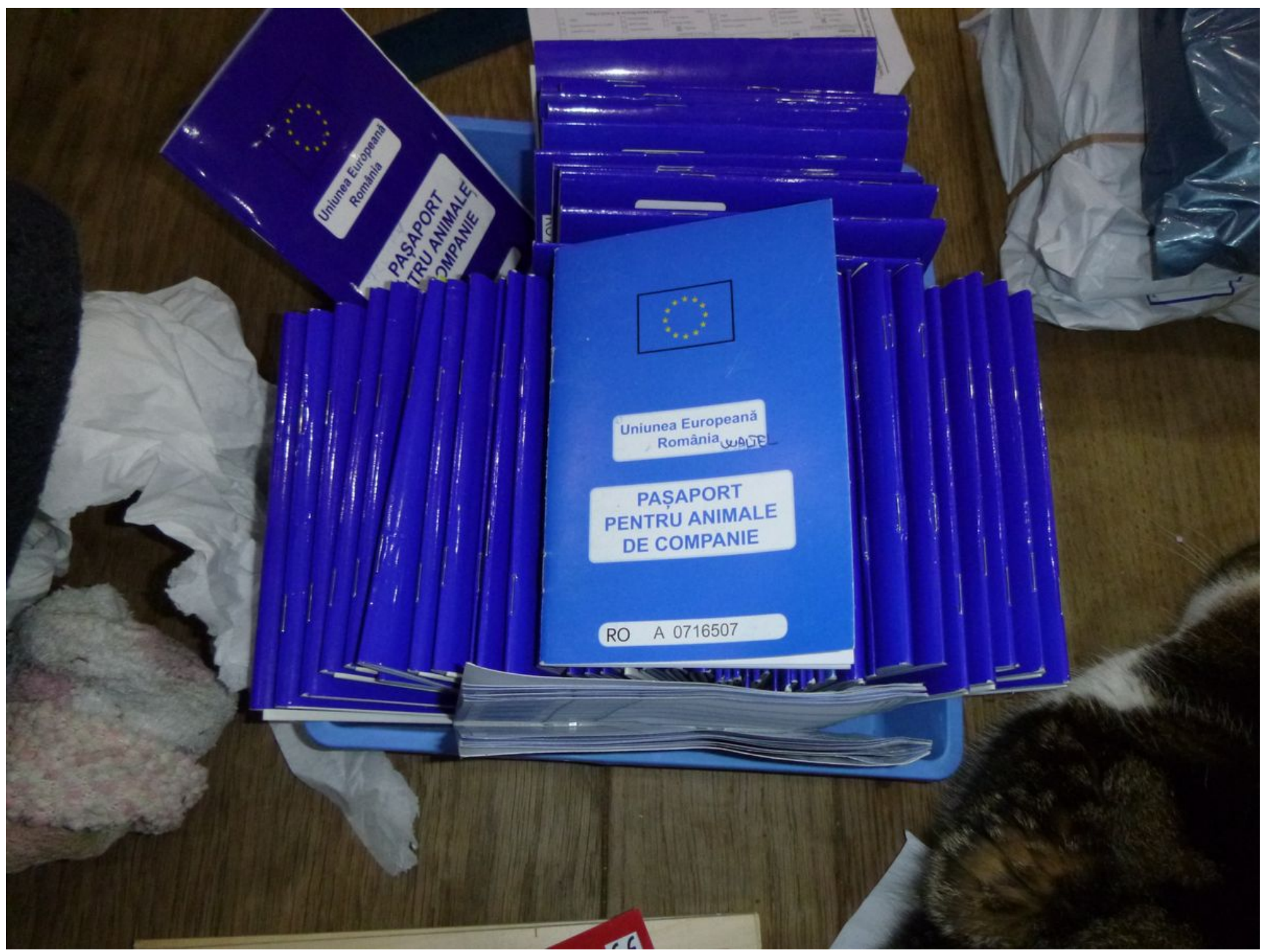

Figure 2

Some of the many Pet Passports found at the 4Paws site 


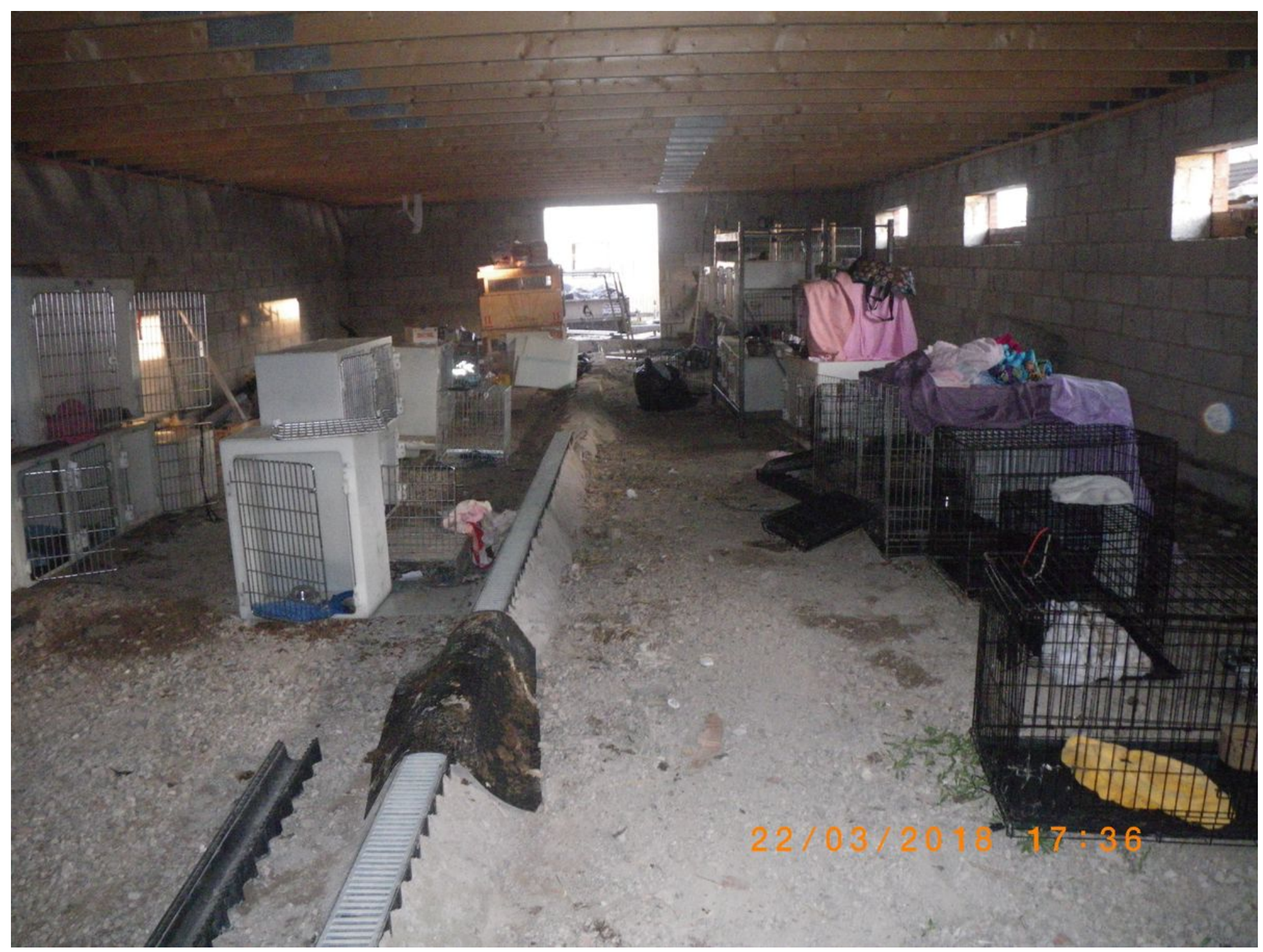

Figure 3

One of the buildings used to house dogs at 4Paws. Note the inadequate and temporary nature of the dogs' accommodation at the site. 


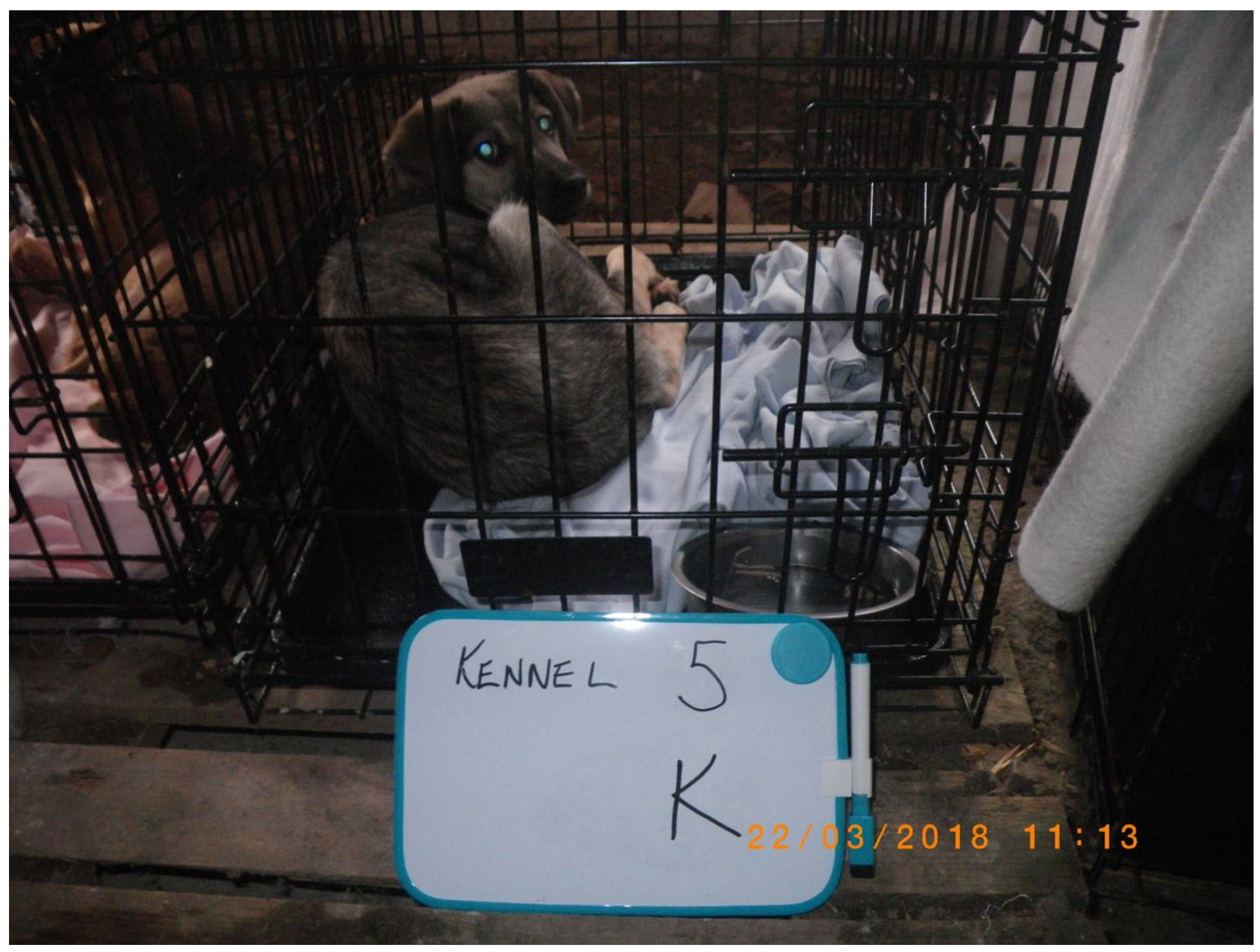

Figure 4

A dog within its permanent accommodation on the 4Paws site. Note the small size, limits on the dog's ability to express normal behaviours and very poor body condition of the dog. 


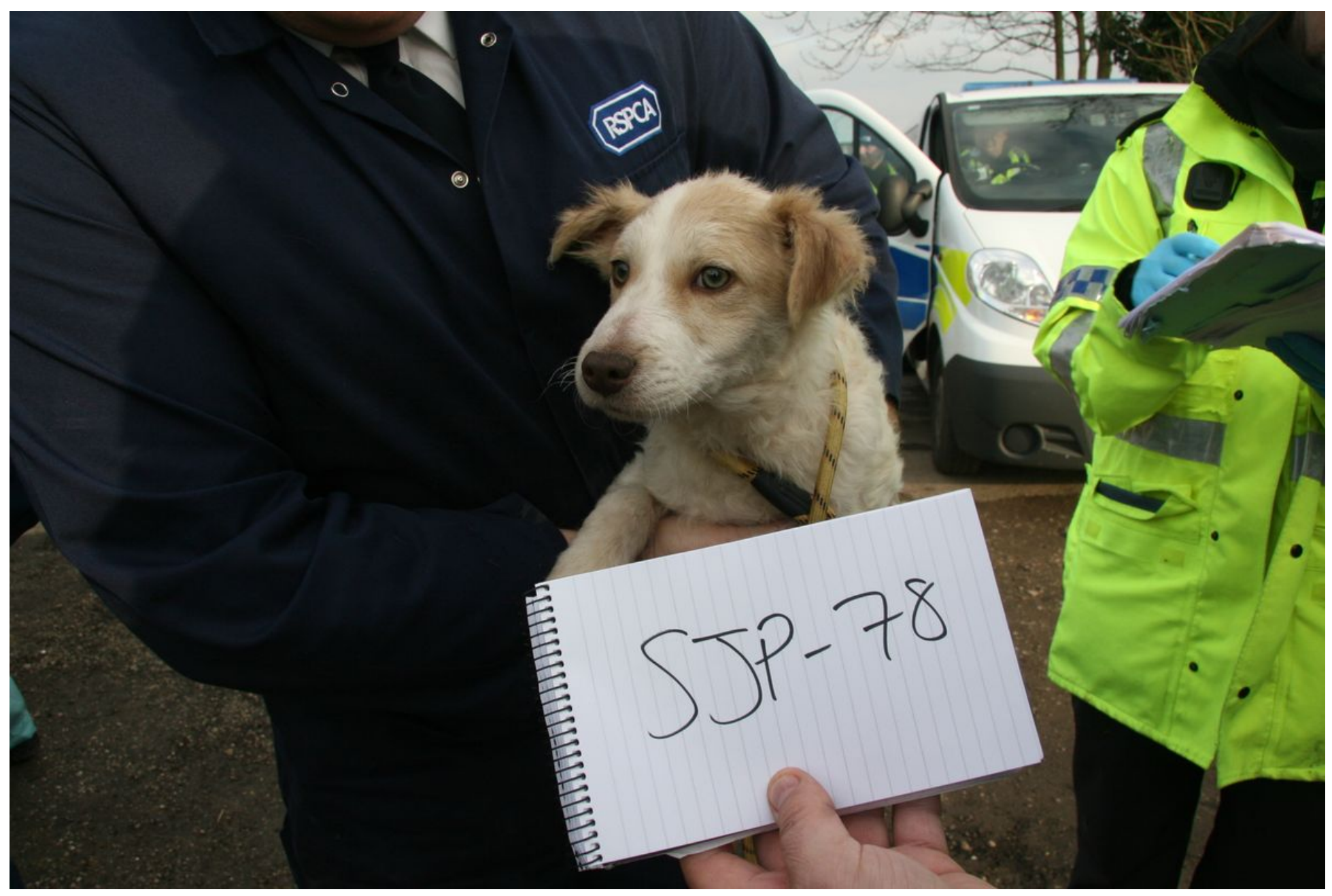

Figure 5

One of the 151 dogs removed from the 4Paws site being identified by the Police and RSPCA before being moved to a safe location.

\section{Supplementary Files}

This is a list of supplementary files associated with this preprint. Click to download.

- graphicalabstract.jpg 